\title{
Akademik Sahtekârlık Ölçeği'nin Türkçeye Uyarlanması: Geçerlik ve Güvenirlik Çalışması
}

\author{
Faruk Caner YAM ${ }^{1}$ ve Seher BALCI ÇELİK ${ }^{2}$
}

\section{$\ddot{O}_{\mathrm{z}}$}

Bu çalışmada Bahsir ve Bala’nın (2017) geliştirdiği altı boyut ve 23 maddeden oluşan Akademik Sahtekârlık Ölçeği’nin Türkçeye uyarlanması amaçlanmıştır. Araştırmanın örneklem grubu 182 erkek ve 230 kadın olmak üzere 412 üniversite öğrencisinden oluşmaktadır. Uyarlama çalışmasında ölçek Türkçeye çevrilmiş ve dil eş değerliği incelenmiştir. Ölçeğin yapısı doğrulayıcı faktör analizi yöntemiyle incelenmiştir. Yapılan analiz sonucunda ölçeğe ait birinci düzey faktör analizi $\left(\chi^{2} / s d=3.21\right.$, GFI $=.98$, IFI $=.93, \mathrm{CFI}=.93$, NFI $=.91 \mathrm{AFGI}=.97$ ve RMSEA $=$ $.073)$ ve ikinci düzey faktör analizi $\left(x^{2} / s d=3.24\right.$, GFI $=.97$, IFI $=.93$, CFI $=.93$, AFGI $=.96$ ve RMSEA $\left.=.074\right)$ sonucunda elde edilen model uyum indekslerinin ölçeğin yapısının Türk örneklemi üzerinde doğrulandığına işaret ettiği görülmüştür. Ayrıca çalışmada Akademik Sahtekârlık Ölçeği’nin Cronbach Alfa iç tutarlık katsayısı 92 bulunmuştur. Diğer açıdan ölçüt geçerliği Akademik Sahtekarlık Ölçeği ile Akademik Sahtekârlık Eğilimi Ölçeği arasındaki korelasyon katsayısı hesaplanmış ve iki ölçekten elde edilen puanlar arasında anlamlı bir ilişkinin olduğu belirlenmiştir. Ayrıca Akademik Sahtekârlık Ölçeği'nin Türkçe formunun ayırt edicilik düzeyini belirlemek için $\% 27$ 'lik alt-üst grup madde puan ortalamaları farklarının anlamlı olup olmadığı, bağımsız gruplar t-testi ile incelenmiş ve ölçme aracının ayırt edicilik özelliğine sahip olduğu sonucuna ulaşılmıştır. Elde edilen sonuçlar alanyazın ışığında tartışılmıştır.

Anabtar Kelimeler: Akademik Sahtekârlık, Geçerlik, Güvenirlik, Ölçek, Uyarlama

\section{Adaptation of Academic Dishonesty Scale to Turkish: Validity and Reliability Study}

\begin{abstract}
In this study, it is aimed to adapt the Academic Dishonesty Scale developed by Bahsir and Bala (2017), which consists of six dimensions and 23 items, into Turkish. The sample group of the research consists of 412 university students, 182 men and 230 women. In the adaptation study, the scale was translated into Turkish and language equivalence was examined. As a result of the analysis, first-level factor analysis $\left(x^{2} / s d=3.21\right.$, GFI $=.98$, IFI $=.93$, $\mathrm{CFI}=.93 \mathrm{NFI}=.91 \mathrm{AFGI}=.97$ and RMSEA $=.073)$ and second-level factor analysis It was seen that the model fit indices obtained as a result of $\left(\chi^{2} / s d=3.24\right.$, GFI $=.97$, IFI $=.93$, CFI $=.93$, AFGI $=.96$ and $\left.\mathrm{RMSEA}=.074\right)$ indicated that the structure of the scale was verified on the Turkish sample. In addition, Cronbach's Alpha internal consistency coefficient of the scale was found.92. On the other hand, the correlation coefficient between the criterion validity Academic Dishonesty Scale and Academic Dishonesty Tendency Scale was calculated and it was determined that there was a significant relationship between the scores obtained from the two scales. In addition, in order to determine the level of discrimination of the Turkish form of the scale, whether the difference between the $27 \%$ sub-upper group item score averages was significant or not was examined with the independent groups t-test and it was concluded that the measurement tool had a distinguishing property. The results obtained were discussed in the light of the literature.
\end{abstract}

Key Words: Adaptation, Academik Dishonesty, Scale, Validity, Reliability

\section{Atıf İçin / Please Cite As:}

Yam, F. C. ve Balcı Çelik, S. (2021). Akademik Sahtekârlık Ölçeği’nin Türkçeye uyarlanması: Geçerlik ve güvenirlik çalışmas1. Manas Sosyal Araștırmalar Dergisi, 10(1), 70-81.

Geliş Tarihi / Received Date: 07.02.2019

Kabul Tarihi / Accepted Date: 24.09.2019

\footnotetext{
1 Öğretim Görevlisi - Gaziosmanpaşa Üniversitesi, Adalet Meslek Yüksek Okulu -farukcanery.yam@gop.edu.tr

(D) ORCID: 0000-0001-8392-9576

2 Prof. Dr. - Ondokuz Mayıs Üniversitesi, Eğitim Fakültesi, Eğitim Bilimleri - sbalci@omu.edu.tr 


\section{Giriş}

Eğitim bireylere istendik yönde davranışlar kazandırma sürecidir (Kılıçoğlu, 2007 s. 32; Baysen, Baysen ve Çakmak, 2017, s. 7). Bu süreçte bireylere eğitim müfredatının içeriğini kazandırmanın yanı sıra istendik yönde davranışlar kazandırmak da hedeflenmektedir (Kılıçoğlu, 2007 s. 32; Baysen, Baysen ve Çakmak, 2017, s. 9). Ancak eğitim süreci içerisinde öğrencilerde etik olmayan davranış örüntüleri de gözlenebilmektedir (Uçak ve Ünal, 2015, s. 255). Etik olmayan davranışlar içeresinde en sık gözlemlenen davranışlar kopya çekme, intihal gibi akademik sahtekârlık davranışlarıdır (Ay ve Çakmak, 2015, s.147; Lanier, 2006, s. 247; Polat; 2017, s. 211). Akademik sahtekârllk öğrencilerin akademik bir araştırmada, sınavda veya projelerinde esnasında kopya çekme, intihal yapma, uydurma ve bozma gibi davranışlara yönelmesi olarak tanımlanmaktadır (Kibler, 1993, s.11; Ömür, Aydın ve Argon, 2014, s.139). Diğer açıdan akademik sahtekârlık kavramı, öğrencinin eğitim-öğretim süreçlerinde daha yüksek notlar elde etmek maksadıyla etik prensipleri göz ardı ederek kopya çekmek, intihal yapma, tahrif etme, proje ve ödevleri kopyalamak gibi davranışlarını ifade etmek için kullanılmaktadır (Lambert, Hogan, ve Barton, 2003, s. 17; Murdock ve Anderman, 2006, s. 135). Bu kavram çok yönlü boyutları olan ve yaygin bir olumsuz öğrenci davranışıdır (Ferrari, 2005 s.14-16; Imran ve Nordin, 2013, s. 111; Ikupa, 1997, s. 38-39; Whitley, 1998, s. 247; Thomas, 2017, s.149). Bu davranışlar eğitim kademesinin her düzeyinde giderek artmakta ve bu durum kayg1 verici bir hal almaya başlamaktadır (Tadesse ve Getachew, 2010, s. 82-84; Uçak ve Ünal, 2015, s. 260; Whitley, 1998, s. 247). Çünkü gelişen ve değişen günümüz bilgi teknolojileri ve bu teknolojilerin öğrenciler tarafindan çok yoğun bir şekilde kullanılması, akademik sahtekârlık davranışlarını gösterme sıklıklarına artışa neden olduğu belirtilmektedir (Aslantaş ve Acar, 2008, s. 38; Hançer, 2017, s. 394; Lin ve Wen, 2007, s. 90; Uçak ve Ünal, 2015, s. 260).

Akademik sahtekârlık kapsamında değerlendirilen en önemli kavram kopya çekme davranışıdır. Kopya kavram1, "bir sanat eserinin veya yaz̨ll bir metnin taklidi", "suret çıkarma işil", "bir sinavda sorular cevaplamak için basska birinden veya yerden gizlice yararlanma" şeklinde tanımlanmaktadır (Türk Dil Kurumu, 2018). Ayrıca bireylerin sinavlarda, projelerde ve ödevlerde izinsiz olarak kaynakları kullanması ve başka yerlerden veya kişilerden elde ettiği bilgileri kendininmiş gibi sunması da kopya davranışı olarak değerlendirilmektedir (Tan, 2001, s. 35-37). Başka bir deyişle kopya çekme, öğrencinin başarılı olmak için sınavdan önce veya sınav sırasında gerçekleştirmiş olduğu etik dişı davranışlarla kendisine veya bir diğer öğrenciye akademik yarar sağlaması durumudur (Özden ve Özdemir-Özden, 2015, s. 93). Yapılan araştırmalar da üniversite öğrencilerinin kopya davranışlarının normal olarak görmediklerini belirtmişlerdir (Barzegar ve Khezri, 2012; Eminoğlu, 2008). Buna rağmen kopya davranışı öğrenciler arasında en yaygın olan akademik sahtekârlık davranışı olduğu görülmektedir (Aluede, Omoregie ve Osa- Edoh, 2006, s. 101; Polat, 2017, s. 2013; Topsakal, 2011, s. 297). Kopya çekme davranış1 eğitim öğretimde ölçme ve değerlendirme faaliyetlerinin (sınav, ödev, proje vb.) geçerli ve güvenilir olmasına engel teşkil eden bir akademik sahtekârlık türüdür (Ay ve Çakmak, 2015, s. 145). Bu nedenle kopya çekme şeklinde gerçekleşen akademik sahtekârlık davranışlarının önüne geçilmesi ve önceden tespiti eğitimdeki kaliteyi arttıracak ve sağlıklı ölçme değerlendirmeyi destekleyecektir.

Akademik sahtekârılık davranışlarından bir diğeri intihaldir. İntihal, basit tanımı ile bir başkasının fikir ve görüşlerini kaynağa ait bilgiler gösterilmeden kullanılması durumudur (Uçak ve Ünal, 2015, s. 261). Diğger bir ifade ile intihal bir başkasına ait bir fikrin bir eserin tamamının veya bir bölümünün başka bir kişinin çalısmasında kendine ait gibi sunması olarak tanımlanmaktadır (Türkiye Bilimler Akademisi, 2000). İtihal davranışının öğrenciler tarafindan kasten ve kasten olmayan şekillerde gerçekleştiği ifade edilmektedir (Maurer, Kappe ve Zaka, 2006, s. 1061). Ancak bu davranış ölçme ve değerlendirme sisteminde kopya çekme davranışı gibi hatalı değerlendirmelere sebep olabileceğinden nedenleri tespit edilmesi önemidir. Yapılan araştırmalarda öğrencilerin intihal davranışının raporlaştırma ve bilimsel yazı yazma konusundaki bilgi eksikliklerinden kaynaklandığı sonucuna ulaşılmıstır (Avaroğulları. 2012 s. 43; Köse ve Arıkan, 2011, s. 125; Dey ve Sobhan, 2006, s. 388-393). Diğer açıdan intihal kavramı konusunda net bir fikir birliğinin olmaması da öğrencilere bu konuda sıkıntılar yaşanmasına neden olduğu ifade edilmektedir (Dames, 2007, s. 24-27).

Birçok öğrenci akademik sahtekârllğı etik dışı davranış olarak nitelendirmesine karşın bu davranışı öğrencilik hayatının belli bir zamanında veya düzenli olarak sergiledikleri saptanmıştır (Eraslan, 2011, s. 55; Grimes, 2004, s. 279; Swift ve Nonis, 1998, s. 32; Yangin ve Kahyaoğlu, 2009, s. 59; Zimerman, 2012, s. 183). Alanyazında öğrencilerin akademik sahtekârlık nedenlerinin incelediği araştırmalar bulunmaktadır. Bu araştırmalarda öğrencilerin akademik sahtekârlık düzeyleri ile öz kontrol düzeyleri (Büyükgöze, 2017, s. 
811; Coşkan, 2010, s. 51; Karim ve Ghavam, 2011, s. 1-8), akademik başarı düzeyleri (Akbulut vd., 2008, s. 469; Kerkvliet ve Sigmund, 1999, s. 339), ahlaki eğilim düzeyleri (Whitley, 1998, s. 251; Roth ve McCabe, 1995, s. 539) arasında negatif yönde ilişkili olduğu rapor edilmiştir. Ayrıca akademik sahtekârlık düzeyinin akademik erteleme (Bricault, 1998), başarısızlık ve not korkusu (Franklyn-Stokes ve Newstead, 1995, s. 164; Seven ve Engin, 2008, s. 131; Swift ve Nonis, 1998, s. 31), olumsuz değerlendirilme korkusu (Ömür ve Aydın, 2014, s. 134), dişsal akademik kontrol odağ1 (Jurdi, Hage ve Chow, 2011, s. 13; Quaye, 2013, s.17) gibi değişkenler ise pozitif yönde ilişkili olduğu ortaya konulmuştur. Diğer açıdan öğrencilerin akademik sahtekârlık eğilimleri üzerinde sınıf arkadaşlarının (Blachnio ve Weremko, 2011, s.-14-19; Nora ve Zhang, 2010, s. 579), internet kullanımınlarının (Orhan ve Günay, 2014, s. 187; Zimerman, 2012), bilgi eksikliğinin (Şahin ve Altınay, 2009; Stubbings ve Brine, 2003), sınav türünün (Büyükgöze, 2017) de etkili olduğu da ifade edilmektedir.

Eğitim-öğretimin ve ölçme değerlendirmenin süreçleri üzerinde olumsuz etkisi olan akademik sahtekârllğın önceden bilinmesi ve öğrencilerin akademik sahtekârlık davranışlarının nedenlerinin çok yönlü olarak saptanmasının önemli olduğu görülmektedir. Alanyazın incelendiğinde bu konuda sadece bir adet ölçme aracının olduğu görülmüştür (Eminoğlu, 2008). Diğer açıdan kopya çekme davranışının değerlendirilmesine yönelik bazı ölçme araçlarının olduğu görülmektedir (Ay ve Çakma, 2015). Ancak alanyazın incelediğinde kopya çekmek akademik sahtekârlık davranışlarının sadece bir boyutunu oluşturduğu dikkati çekmektedir. Tüm bu gerekçelerle bu araştırmada Bahsir ve Bala (2017) tarafindan geliştirilen 6 boyut ve 23 maddeden oluşan Akademik Sahtekârlık Ölçeği’nin (Academic Dishonesty Scale) Türkçeye uyarlanması amaçlanmıştır. Bu çalışmanın öğrencilerin akademik sahtekârlık düzeylerinin çok boyutlu bir şekilde değerlendirmesi sürecine katkı sağlayacağı düşünülmektedir.

\section{Yöntem}

\section{Araştırma Modeli}

$\mathrm{Bu}$ araş̧ırma betimsel tarama modelinde tasarlamış bir çalışmadır. Betimsel tarama modellerinde araştırmacı incelediği değişkenler arasındaki ilişkiyi herhangi bir müdahalede bulunmadan olduğu gibi betimlemeyi amaçladığı bir araştırma desenidir (Böke, 2014, s. 164). Diğer bir ifade ile betimsel tarama modellerinde araştırılan olay ve olguların elde edilen veriler doğrutusunda olduğu gibi açıklanması amaçlanmaktadır (Büyüköztürk vd., 2017, s.232).

\section{İşlem}

Birinci aşamada önce ölçeği geliştiren araştırmacılar Bahsir ve Bala'dan (2017) e-mail yolu ile izin alınmıştır. İkinci aşamada ölçeğin orijinal formu 3 İngilizce uzmanına gönderilerek, ölçeğin Türkçe çevirilerinin yapılması sağlanmıştır. Üçüncü aşamada İngilizce uzmanlarında gelen çeviriler iki tane Eğitim Bilimleri alan uzmanına gönderilerek, maddelerin Türkçe çevirilerinin uygun olup olmadığının değerlendirilmesi sağlanmıştır. Dördüncü aşamada Eğitim Bilimleri alan uzmanlarından gelen dönütlerden sonra oluşturulan ölçek formu Türkçe gramer ve anlaşılabilirlik açısından incelenmesi için iki tane Türk Dili ve Edebiyatı uzmanına gönderilmiş, onlardan gelen dönütler sonrası gerekli düzenlemeler yapılarak ölçeğe son hali verilmiştir. Beşinci aşamada ölçeğin dil eşdeğerlik düzeyinin belirlenmesi için ölçeğin İngilizce ve Türkçe formu her iki dili bilen 20 kişilik bir gruba uygulanmış ve her iki uygulama arasındaki benzerlik korelasyon katsayısı ve bağımlı gruplar $t$-testi ile incelenmiştir Son aşamada ölçek formu ile 412 üniversite öğrencisine uygulanmış ve ölçeğin yapı geçerliği doğrulayıcı faktör analizi ile incelenmiştir.

\section{Araştırma Grubu}

Çalışmaya Orta Karadeniz Bölgesi'ndeki bir ilde bulunan üniversitedeki 182 erkek ve 230 kadın olmak üzere 412 üniversite öğrencisi katılmıştır. Öğrencilerin yaşları 18 ile 25 arasında $(\bar{x}=20.91 ; S s=$ 1.56), sinıf düzeyleri ise 1 ile 4 arasında $(\bar{x}=2.90 ; \mathrm{Ss}=1.16)$ değişmektedir.

\section{Veri Toplama Araçları}

Kişisel Bilgi Formu. Araştırmaya katılan üniversite öğrencilerinin cinsiyet, sınıf düzeyi, yaş ve okudukları bölümlerle ilgili bilgilerin alınması için araştırmacı tarafından oluşturulmuştur

Akademik Sabtekârllk Ölçeği (ASÖ). Bahsir ve Bala (2017) tarafindan geliştirilen Akademik Sahtekârllk Ölçeği'nin orijinal formu 23 maddeden oluşmaktadır. Ölçek sınav esnasında hile (5 madde), intihal (4 madde), dış yardım (4 madde), kopya için ön hazırlık ( 3 madde), tahrif-uydurma (3 madde) ve akademik ödevler hakkında yalan/bahane (4 madde) olmak üzere toplam altı alt boyuttan oluşmaktadır. Ölçek beşli 
likert tipinde hazırlanmış ve ölçekten alınabilecek puanlar 23-115 arasında değişmektedir. Ölçekte hiç ters madde bulunmamaktadır. Orijinal ölçeğin geliştirilme aşamasında geçerlik ve güvenirlik çalışmaları için öncelikle açımlayıcı faktör analizi yapılmıştır. Analizin sonucuna göre KMO (.89) ve Bartlett's Test of Sphericity $($ Chi-square $=2610.357 ; \mathrm{p}<.01)$ sonucuna ulaşılmıstır.

Araştırmacılar (Bahsir ve Bala, 2017) tarafından ikinci aşamada açımlayıcı faktör analizi ile ortaya çıkan yapının geçerliliğin incelemek için doğrulayıcı faktör analizi yapılmışlardır. Analiz sonucunda elde ettikleri modele uyum indekslerinin $\left(x^{2} / s d=2.173\right.$; GFI $=.915$; AGFI $=.901$; CFI $=.870$; RMSEA $\left.=.051\right)$ iyi uyuma işaret ettiğini ifade etmişlerdir. Ayrıca güvenirlik analizi için Cronbach' Alfa iç tutarlılık katsayısı hesaplamış ve .83 bulunarak ölçümlerin güvenilir olduğunu belirtmişlerdir. Diğer açıdan ölçeğin orijinal geliştirme sürecine ait yayında, alt boyutlara ait iç güvenirlik katsayılarına yer verilmemiştir.

Akademik Sabtekârllk Eğilim Ölçeği (ASEÖ). Ölçek Eminoğlu'nun (2008) tarafindan geliştirilmiştir. Araştırmacı öncelikli olarak toplamış olduğu verilerinin açımlayıcı faktör analizine uygun olup olmadığını incelemiştir (KMO $=.90$ ve Bartlett's Test of Sphericity $\left.x^{2}=2672.233, \mathrm{p}<.01\right)$. Ardindan toplanan veriler üzerinde gerçekleştirilen açımlayıcı faktör analizi sonucunda 4 boyutlu ve 22 maddeden oluşan bir yapı elde etmiştir. Daha sonra açımlayıcı faktör analizi ile ortaya çıkan yapının doğrulayıcı faktör analizi incelenmiş ve analiz sonucunda elde edilen model uyum indekslerine $\left(x^{2} / s d=1.865\right.$; GFI $=.96$; AGFI $=.95$; CFI $=.93$; RMSEA =.057) ölçeğin iyi uyum gösterdiği sonucuna ulaşmışlardır. Diğer açıdan araştırmacı geliştirmiş olduğu Akademik Sahtekarlık Eğilimi Ölçeği’nin güvenirlik katsayısı Cronbach Alfa iç tutarlılık katsayısı .90 hesaplamıştır.

\section{Etik Kurallara Uygunluk}

Araştırmada bütün etik koşullar sağlanmış, araştırmaya katılan öğrencilere gönüllü katılım formu ve bilgilendirilmiş onam formu verilerek araştırma hakkında bilgilendirilmiş, araştırmanın veri toplama süreci gönüllülük esası göz önüne alınarak sürdürülmüştür. Ayrıca araştırma için Ondokuz Mayıs Üniversitesi Sosyal ve Beşeri Bilimler Etik Kurulu'ndan 29/05/2020 tarib ve 2020/292 karar saynll etik kurul izni alınmıştır. Diğer açıdan çalışmanın verileri konusu itibari ile gizlilik esasına dikkat edilmiş veri toplama araçları da bu hassasiyet gözetilerek hazırlanmış ve sonrasında muhafaza edilmiştir.

\section{Verilerin Analizi}

Çalışma sürecinde Akademik Sahtekârlık Ölçeği (ASÖ) 'nin yapı geçerliği doğrulayıcı faktör analiziyle incelenmiştir. Doğrulayıc1 faktör analizi bir teorinin veya modeli yap1 geçerliğinin test edilmesinde kullanılan bir analiz yöntemidir (Tabachnick ve Fidell, 2013, s. 81). Doğrulayıcı faktör analizinde elde edilen yapının doğrulanıp doğrulanmadığına model uyum indeksleri incelenerek karar verilmektedir. (Şencan, 2005). Bu araştırmada doğrulayıc1 faktör analizi sonuçları değerlendirilirken $\chi^{2} / s d$, RMSEA, AGFI, TLI, CFI IFI, RFI, GFI, NFI model uyum indeksleri kullanılmıştır. Model uyum indeksleri değerlendirilirken AGFI $\geq .85$ ve GFI, TLI, CFI ve NFI $\geq .90$ (Hu ve Bentler, 1999, s. 37-41) olmas1 beklenmektedir. Ayrıca RMSEA'nın .080'in altında olması iyi model uyumuna, .010 'dan küçük olması ise modelin kabul edilebilir olduğuna işaret etmektedir (Hu ve Bentler, 1999; Tabachnick ve Fidell, 2013, s. 83). Diğer taraftan $x^{2} / s d$ katsayının iki ve altında olması iyi uyuma, beş kadar olması ise kabul edilebilir uyum olarak değerlendirilmektedir. Araştırmada ölçüt geçerliği için Akademik Sahtekarlık Ölçeği ile Akademik Sahtekârlık Eğilim Ölçeği arasından Pearson Momentler Çarpımı (r) korelasyon katsayısı hesaplanmıştır. Diğer açıdan ASÖ'nün Türkçeye uyarlanan formunun ayırt edici bir ölçüm yapıp yapmadığını incelemek için yüzde 27'lik alt-üst grupların madde toplam puan ortalamaları arasındaki farkın anlamlı olup olmadığı bağımsız gruplar $t$-testiyle analiz edilmiştir. Araştırmada kullanılan ölçme araçlarının güvenirlik analizi için Cronbach Alfa iç tutarlık katsayısı (Cronbach' Alpha) hesaplamışır. Araştırmada SPSS23 ve AMOS23 istatistik programları kullanılmışır.

\section{Bulgular}

\section{ASÖ’nün Dil Geçerliğine İlişkin Bulguları}

Ölçme aracının dil geçerliğinin incelemek için ölçeğin İngilizce ve Türkçe ölçek formu her iki dili bilen 20 kişilik bir gruba uygulanmış, iki uygulama arasındaki hesaplanan korelasyon katsayısı $(r=.95 ; \mathrm{p}<$ .001) ve bağımlı gruplar $t$-testi sonuçlarına $\left(t_{(19)}=.725 ; \mathrm{p}=.49 ; \mathrm{p}>.05\right)$ göre ölçeğin Türkçe formunun anlaşılabilir olduğu sonucuna ulaşılmıştır. 


\section{ASÖ’nün Doğrulayıcı Faktör Analizi Bulguları}

Akademik Sahtekârlık Ölçeği’nin (ASÖ) Türk örneklem gurubundaki yapısı doğrulayıcı faktör analizi ile incelenmiştir. Araştırmalarda doğrulayıcı faktör analizi bulguları $x^{2} / s d$, RMSEA, AGFI, TLI, CFI IFI, RFI, GFI, NFI şeklindeki uyum iyiliği indekslerine göre yorumlanmaktadır (Kline, 2005, s. 61; Tabachnick ve Fidell, 2013, s. 85). Yapılan birinci düzey faktör analizi sonrası elde edilen model uyum indeksleri $x^{2} / d f$ $=3.21 \mathrm{GFI}=.98, \mathrm{IFI}=.93, \mathrm{CFI}=.93, \mathrm{NFI}=.91 \mathrm{AFGI}=.97$ ve RMSEA $=.073$ olarak hesaplanmış ve ölçeğin kabul edilebilir düzeyde uyum sağladığı görülmüştür. Birinci düzey faktör analizine sonucunda oluşan modele ilişkin path diyagramı Şekil-1'de verilmiştir.

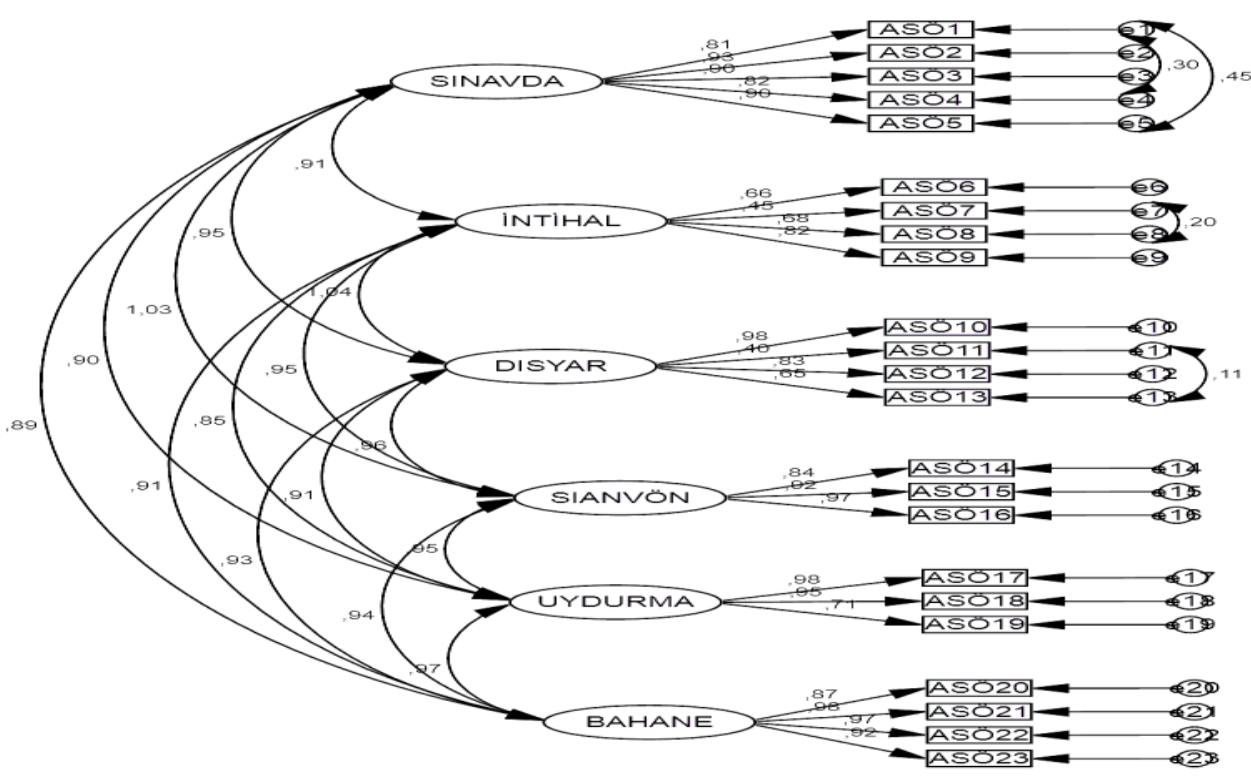

Şekil 1. Birinci Düzey Doğrulayıcı Faktör Analiz Path Diyagramı

Daha sonra örtük yapının doğrulanıp doğrulanmadığını incelemek için ikinci düzey doğrulayıcı faktör analizi yapılmıştır. Yapılan analiz sonucu $x^{2} / d f=3.22$, GFI $=.97$, IFI $=.93$, CFI $=.93$, AFGI $=$ .97 ve RMSEA = .074 olarak hesaplanmıştır. Bu sonuca göre ölçeğin ikinci düzey doğrulayıcı faktör analiz sonuçlarının kabul edilebilir düzeyde olduğu görülmüștür. İkinci düzey doğrulayıcı faktör analizi sonucu ortaya çıkan diyagram Şekil-2'de verilmiştir.

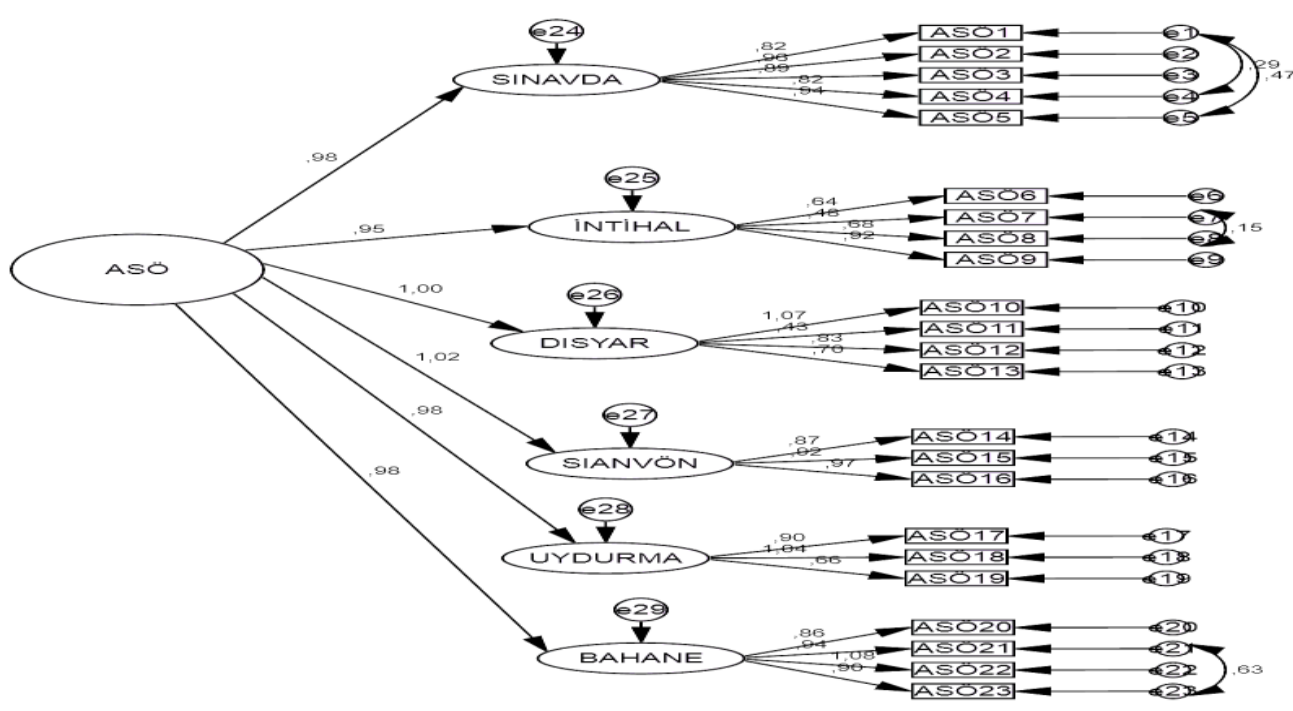

Şekil 2. İkinci Düzey Doğrulayıı Faktör Analiz Path Diyagramı 


\section{ASÖ’nün Benzer Ölçek Geçerliğine İlişkin Bulgular}

Benzer ölçek geçerliğini incelemek için Akademik Sahtekarlık Ölçeği (ASÖ) ile 326 katılımcıya uygulanan Akademik Sahtekarlık Eğilimi Ölçeği (ASE) arasındaki Pearson momentler çarpımı korelasyon katsayısı hesaplanmıştır. Analizin sonucuna göre ASÖ ile ASE arasında pozitif olarak anlamlı bir ilişkinin olduğu görülmüş̧ür $(\mathrm{r}=.66, \mathrm{p}<.01)$.

\section{ASÖ'nün Madde Analizi Bulguları}

Ölçeğin ayırt edici bir ölçüm yapıp yapmadığ $\% 27$ 'lik alt grup ve \%27’lik üst grup madde puan ortalamaları arasındaki fark incelenerek karar verilmiştir. Bunun farkın anlamlı olup olmadığını belirlenmesi için yapılan bağımsız gruplar $t$-testi analizi gerçekleştirilmiştir. Ayrıca ölçekte yer alan maddelerin hem ölçeğin geneliyle hem de kendi alt boyutuyla olan düzeltilmiş madde toplam korelasyonları da hesaplanmıstır. Bu analizlere ilişkin tüm sonuçlara Tablo 1'de yer verilmiştir.

Tablo 1. Akademik Sabtekârlk Ölçeği Madde Analizi Sonuclar

\begin{tabular}{|c|c|c|c|c|c|c|c|}
\hline \multirow{2}{*}{$\begin{array}{l}\text { Boyut/ Madde No } \\
\text { Sinav Anında }\end{array}$} & \multicolumn{2}{|c|}{$\begin{array}{l}\text { Düzeltilmiş Madde } \\
\text { Toplam Korelasyonları }\end{array}$} & \multicolumn{2}{|c|}{$\begin{array}{l}\text { Alt \%27 } \\
(\mathrm{n}=111)\end{array}$} & \multicolumn{2}{|c|}{$\begin{array}{l}\text { Üst \%27 } \\
(\mathrm{n}=111)\end{array}$} & $t$ \\
\hline & $\begin{array}{l}\text { Madde- } \\
\text { Boyut }\end{array}$ & $\begin{array}{l}\text { Madde- } \\
\text { Ölçek }\end{array}$ & $\bar{x}$ & $\mathrm{~S}$ & $\bar{x}$ & $\mathrm{~S}$ & \\
\hline ASÖ1 & .75 & .65 & 1.13 & .41 & 3.07 & 1.25 & $-15.61 *$ \\
\hline ASÖ2 & .70 & .70 & 1.02 & .14 & 2.20 & 1.35 & $-9.19 *$ \\
\hline ASÖ3 & .72 & .69 & 1 & .01 & 1.91 & 1.21 & $-7.92 *$ \\
\hline ASÖ4 & .68 & .64 & 1.05 & .26 & 2.47 & 1.31 & $-11.18^{*}$ \\
\hline ASÖ5 & .74 & .65 & 1.02 & .13 & 2.68 & 1.20 & $-14.47^{*}$ \\
\hline \multicolumn{8}{|l|}{ İntihal } \\
\hline ASÖ6 & .48 & .51 & 1.08 & .34 & 2.16 & 1.28 & $-8.59 *$ \\
\hline ASÖ7 & .42 & .42 & 1.61 & .68 & 3.03 & 1.14 & $-11.30^{*}$ \\
\hline ASÖ8 & .48 & .44 & 1.24 & .53 & 2.64 & 1.43 & $-9.64 *$ \\
\hline ASÖ9 & .54 & .58 & 1.01 & .094 & 1.96 & 1.28 & $-7.85^{*}$ \\
\hline \multicolumn{8}{|l|}{ Dış Yardım } \\
\hline ASÖ10 & .42 & .63 & 1.01 & .02 & 1.82 & 1.29 & $-6.67 *$ \\
\hline ASÖ11 & .31 & .33 & 2.08 & .94 & 3.28 & 1.20 & $-8.30^{*}$ \\
\hline ASÖ12 & .51 & .64 & 1.02 & .13 & 2.18 & 1.24 & $-9.84 *$ \\
\hline ASÖ13 & .38 & .40 & 1.41 & .73 & 3.22 & 1.25 & $-13.19 *$ \\
\hline \multicolumn{8}{|l|}{ Sınav Öncesi } \\
\hline ASÖ14 & .63 & .61 & 1.12 & .32 & 2.99 & 1.24 & $-15.44 *$ \\
\hline ASÖ15 & .72 & .67 & 1.01 & .03 & 3.01 & 1.29 & $-16.41 *$ \\
\hline ASÖ16 & .63 & .65 & 1.03 & .16 & 2.63 & 1.39 & $-12.04 *$ \\
\hline \multicolumn{8}{|l|}{ Uydurma/Tahrif } \\
\hline ASÖ17 & .54 & .58 & 1.01 & .01 & 1.92 & 1.21 & $-8.02 *$ \\
\hline ASÖ18 & .63 & .54 & 1.02 & .18 & 1.46 & 1.04 & $-4.39 *$ \\
\hline ASÖ19 & .48 & .48 & 1.09 & .28 & 2.03 & 1.21 & $-7.94 *$ \\
\hline \multicolumn{8}{|l|}{ Bahane Üretme } \\
\hline ASÖ20 & .66 & .59 & 1.07 & .29 & 2.64 & 1.36 & $-11.87 *$ \\
\hline ASÖ21 & .61 & .60 & 1.02 & .13 & 2.17 & 1.34 & $-9.02 *$ \\
\hline ASÖ22 & .56 & .45 & 1.02 & .01 & 1.64 & 1.17 & $-5.74 *$ \\
\hline ASÖ23 & .54 & .56 & 1.03 & .16 & 2.12 & 1.22 & $-9.28^{*}$ \\
\hline
\end{tabular}

${ }^{*} \mathrm{p}<.001$ 
Tablo 1'de görüldüğü üzere maddelerin ayırt ediciliğini incelemek için yapılan bağımsız gruplar $t$ testi sonucuna göre tüm maddelerin ayırt edicilik özelliğine sahip olduğu ortaya çıkmıştır. Diğger bir ifade ile \%27'lik alt ve \%27'lik üst gruplardan elde edilen madde ortalamaları arasındaki farkın tüm maddeler için $\mathrm{p}<.001$ düzeyinde anlamlı olduğu görülmüştür. Ayrıca düzetilmiş madde toplam korelasyonlarına incelendiğinde her maddenin tüm ölçekle ve kendi alt boyutu ile yeteri düzeyde ilişkili görülmektedir.

\section{ASÖ'nün Güvenirlik Çalışmasına İlişkin Bulgular}

Akademik Sahtekârlık Ölçeği (ASÖ) ile Akademik Sahtekârlık Eğilimi Ölçeği (ASE) için güvenirliği Cronbach Alfa iç tutarlık katsayısı hesaplanmışır. ASÖ'nün Cronbach Alfa iç tutarlık katsayısı ölçeğin tamamı için .92, sınav anında aldatma boyutu için .88, intihal boyutu için .70 , dış yardım alt boyutu için .60 , sınav öncesi aldatma boyutu için .81, uydurma/tahrif boyutu için .72 ve bahane bulma boyutu için .78 olarak hesaplanmıştır. Benzer ölçek geçerliği için kullanılan ASEÖ'nin Cronbach Alfa katsayısı ise .84 olarak hesaplanmıştır. Bu sonuçlar yapılan bütün ölçümlerin güvenilir olduğunu göstermektedir.

\section{Tartışma, Sonuç ve Öneriler}

Bu çalışmanın amacı Bahsir ve Bala (2017) tarafından geliştirilen Akademik Sahtekârlık Ölçeğini geçerlik ve güvenirlik çalışmasının yapılarak Türk kültürüne uyarlamasıdır. Bunun için öncelikli olarak dil geçerliliğinin test edilmesi amaçlamış, ölçeğin İngilizce ve Türkçe formu iki dili bilen bir gruba uygulanmıştır. Uygulamadan sonra her iki formdan elde edilen puanlar arasındaki korelasyon katsayısı hesaplanmış, ölçeğin Türkçe ve İngilizce formları arasında yüksek oranda ilişki olduğu tespit edilmiştir ( $\mathrm{r}=$ $.95 ; \mathrm{p}<.001)$. Aynı zaman ölçeğin Türkçe ve İngilizce formundan elde edilen puanlar arasındaki ilişkiyi incelemek için bağımlı gruplar $t$-testi analizi yapılmıştır. Yapılan analiz sonucunda iki formdan elde edilen puanlar arasındaki anlamlı bir farkın olamadığı tespit edilmiştir $\left(\mathrm{t}_{(19)}=.725 ; \mathrm{p}=.49 ; \mathrm{p}>.05\right)$. Bu sonuçlar ölçeğin Türkçe ve İngilizce formunun okuyucular tarafından aynı şekilde algılandığı ve dilsel açıdan eşdeğer olduğuna işaret etmektedir.

Dil geçerliliği sağlandıktan sonra ölçeğin yapı geçerliği doğrulayıcı faktör analiz ile incelenmiştir. Araştırmada ilk olarak birinci düzey faktör analizi yapılmış ve elde edilen model uyum indekslerinin kabul edilebilir düzeyde olduğu saptanmıştır $\left(x^{2} / s d=3.21\right.$, GFI $=.98, \mathrm{IFI}=.93, \mathrm{CFI}=.93$, NFI $=.91 \mathrm{AFGI}=$ .97 ve RMSEA = .073). Daha sonra ölçeğin örtük yapısının doğrulanıp doğrulanmadı̆̆ını incelemek için ikinci düzey doğrulayıc1 faktör analizi gerçekleştirilmiş ve elde edilen model uyum indekilerinin kabul edilebilir sınırlarda olduğu görülmüştür $\left(x^{2} / s d=3.22\right.$, GFI $=.97$, IFI $=.93$, CFI $=.93$, AFGI $=.97$ ve RMSEA = .074). Birinci ve ikinci düzey doğrulayıcı faktör analizi sonuçları Akademik Sahtekârlık Ölçeğinnin Türk örnekleminden toplanan veriler üzerinde doğrulandığına ve geçerli bir ölçme aracı olduğuna işaret etmektedir.

Ölçeğin benzer ölçek geçerliği çalışması için Akademik Sahtekârlık Ölçeği (ASÖ) ile Akademik Sahtekârlık Eğilimi Ölçeği(ASEÖ)'nden elde edilen puanlar arasındaki korelasyon katsayısı incelenmiştir. Yapılan inceleme soncunda ASÖ ile ASEÖ elde edilen puanlar arasında pozitif yönde anlamlı ilişkilinin olduğu görülmüştür. Bu sonuç ölçeğin benzer ölçek geçerliliğinin sağladığını göstermektedir. Ölçeğin ayırt edici bir ölçüm yapıp yapmadığı yüzde 27'lik alt grup ve üst grup madde puan ortalamaları arasındaki fark incelenerek karar verilmiştir. Yapılan bu analize göre \%27'lik alt ve \%27'lik üst gruplardan elde edilen madde ortalamaları arasındaki farkın tüm maddeler için $\mathrm{p}<.001$ düzeyinde anlamlı olduğu ortaya çımıştır. Diğer bir ifadeyle bu sonuç tüm maddelerin ayırt edicilik özelliğine sahip olduğuna işaret etmektedir. Ayrıca maddelerin düzetilmiş madde toplam korelasyonlarına incelenmiş ve her maddenin tüm ölçekle ve kendi alt boyutu ile yeteri düzeyde ilişkili olduğu görülmüştür.

Son olarak ölçeğin güvenirlik analizi için Cronbach Alfa iç tutarlık katsayısı hesaplamış ve ölçeğin tamamı için .92, sınav anında aldatma boyutu için . 88, intihal boyutu için .70, dış yardım alt boyutu için .60 , sınav öncesi aldatma boyutu için .81, uydurma/tahrif boyutu için .72 ve bahane bulma boyutu için .78 olarak hesaplanmıştır. Bu sonuçlara göre ölçeğin yüksek düzeyde güvenirliğe sahip olduğu söylenebilir.

Sonuç olarak yapılan uyarlama çalışmasında Akademik Sahtekârlık Ölçeği’nin Türk örnekleminden elde edilen veriler üzerinde doğrulandığı ortaya çıkmıştır. Bu sonuçlar ölçme aracının sonraki çalışmalarda geçerli ve güvenilir sonuçlar vereceği şeklinde yorumlanabilir. 


\section{Etik Beyan}

Araştırmada bütün etik koşullar sağlanmış, araştırmaya katılan öğrencilere gönüllü kattılım formu ve bilgilendirilmiş onam formu verilerek araştırma hakkında bilgilendirilmiş ve araştırmanın veri toplama sürecinde gönüllülük esası göz önüne alınarak sürdürülmüştür. Ayrıca Ondokuz Mayıs Üniversitesi Sosyal ve Beşeri Bilimler Etik Kurulu'ndan 29/05/2020 tarih ve 2020/292 karar sayll etik kurul izni alınmıştır. Diğer açıdan çalışmanın verileri konusu itibari ile gizlilik esasına dikkat edilmiş veri toplama araçları da bu hassasiyet gözetilerek hazırlanmış ve sonrasında muhafaza edilmiştir. Sonuç olarak araştırmanın insan katılımcıları içeren çalışmalarda gerçekleştirilen tüm etik prosedürlerin sağlandığını beyan ederim.

\section{Kaynakça}

Akbulut, Y., Şendă̆, S., Birinci, G., Kilıçer, K., Şahin, M.C. ve Odabaşı, H. F. (2008). Exploring the types and reasons of Internet-triggered academic dishonesty among Turkish undergraduate students: development of Internet-triggered academic dishonesty scale (ITADS). Computers and Education, 51(1), 463-473.

Albers-Miller, N. D., Straughan R. D. ve Prenshaw P. J. (2000). The relationship between cheating and university choice: An analysis of student perceptions". İçinde Capozzoli E.A.,Tudor R.K., and McKee D, (Ed.), Advances in Marketing, Southwestern Marketing Association, Troy State University and Kennesaw State University.

Antonio, D. L. ve Michael, W. B. (1983). Short-term predictive validity of demographic, affective, personal and cognitive variables in relation to 2 criterion measures of cheating behaviors. Educational and Psychological Measurement, 43(2), 467-483.

Aluede, O., Omoregie, E. O ve Osa-Edoh, G. I. (2006). Academic dishonesty as a contemporary problem in higher education: How academic advisors can help. Reading Improvement, 43 (2), 97-106.

Arslantaş, C. C. ve Acar, G. (2008). Perceptions of academic and business dishonesty among senior level students. Yönetim, 60, 32-49.

Avaroğullar1, M. (2012). Sosyal bilgiler ögretmen adaylarmm ve ögretim elemanlarnmn intibal problemine yönelik tutum ve davranısları. Yayınlanmamış yüksek lisans tezi. Gazi Üniversitesi Eğitim Bilimleri Enstitüsü, Ankara.

Baysen, F., Baysen, E. ve Çakmak, N. (2017). Lise öğrencilerinin intihal ile ilgili kavram yanılgglarının giderilmesinde uluslararası Bakalorya Programı'nın etkisi. Bilgi Dünyası, 18 (1), 1-20.

Błachnio, A., \& Weremko, M. (2011). Academic cheating is contagious: The influence of the presence of others on honesty. A study report. International Journal of Applied Psychology, 1(1), 14-19.

Barzegar, K., \& Khezri, H. (2012). Predicting academic cheating among the fifth grade students: The role of selfefficacy and academic self-handicapping. Journal of Life Science and Biomedicine, 2(1), 1-6.

Büyükgöze, H. (2017). Öğretmen adaylarının akademik sahtekârllk eğilimlerinde öz yeterlik ve akademik kontrol odağının rolü. MCBÜ Sosyal Bilimler Dergisi, 15 (1), 801-822.

Büyüköztürk, Ş. (2014). Sosyal bilimler için veri analizị el kitabı. Ankara: Pegem Akademi.

Böke, K. (2014). Sosyal bilimlerde arasstrma yöntemleri.(4. Baski). İstanbul: Alfa Yayınları.

Bricault, D. (1998). Legal aspects of academic dishonesty: Policies, perceptions, and realities. Retrieved Sept, 15, 2004.

Certel, Z., Bahadır, Z., Saracaloğlu, S. ve Varol, R. (2017). Beden eğitimi öğretmen adaylarının kopya çekme eğilimleri ve akademik kontrol odaklarının incelenmesi. Eğitim ve Öğretim Araştırmalarn Dergisi, 6 (2), 259-271.

Cosskan, C. (2010). The effects of self-control and social influence on academic dishonesty: An experimental and correlational investigation. Master's thesis. Middle East Technical University, Ankara.

Dames, K.M. (2007). Understanding plagiarism and how it differs from copyright infringement. Computers in Libraries, $27(6), 24-27$.

Dey, S.K. ve Sobhan, M. A. (2006). Impact of unethical practices of plagiarism on learning, teaching and research in higher education: some combating strategies. Information Tecbnology Based Higher Education and Training, 2006. ITHET'06. 7th International Conference içinde (s. 388-393).

Ersoy, A. (2014). İnternet kaynaklarından intihal yaptığımın farkında değildim: Bir olgubilim araştırması. Pamukkale Üniversitesi Ë̆itim Fakïltesi Dergisi, 35, 47-60.

Eraslan, A. (2011) Matematik öğretmen adayları ve kopya: Hiç çekmedim desem yalan olur!. Eğitim ve Bilim, 36(160), 52-64.

Franklyn-Stokes, A., ve Newstead, S. E. (1995). Undergraduate cheating: who does what and why?. Studies in bigher education, 20(2), 159-172.

Ferrari, J. R. (2005). Impostor tendencies and academic dishonesty: Do they cheat their way to success? Social Behavior and Personality: an international journal, 33(1), 11-18.

Gümüşgil, O. Üstün, Ü. D., Işıı, U. ve Demirel, D.H. (2013). Beden eğitimi ve spor yüksekokulu öğrencilerinin akademik sahtekârlık eğilim düzeylerinin değerlendirilmesi. Ankara Üniversitesi Spor Bilimleri Fakeulltesi Dergisi, 11(2), 131-138.

Grimes, P. W. (2004). Dishonesty in academics and business: A cross-cultural evaluation of student attitudes. Journal of Business Etbics, 49(3), 273-290.

Haines, V. J., Diekhoff, G. M., LaBeff, E. E. ve Clark, R. E. (1986). College cheating: Immaturity, lack of commitment, and the neutralizing attitude. Research in Higher Education, 25(4), 342-54. 
Hu, L.T., ve Bentler, P.M.(1999). Cut off criteria for fit indexes in covariance structure analysis: Conventional criteria versus new alternatives. Structural Equation Modeling, 6(1), 1-55.

Ikupa, J. C. B. (1997). Causes and cure of examination malpractices. The Business Administrator, 1(1), 38-39.

Imran, A. M., \& Nordin, M. S. (2013). Predicting the underlying factors of academic dishonesty among undergraduates in public universities: a path analysis approach. Journal of Academic Ethics, 11(2), 103-120.

Hançer, A. H. (2017). Fen bilgisi öğretmen adaylarının öğretmenlik mesleğine yönelik tutumlarının akademik sahtekârlık eğilimleri üzerindeki etkisi. Electronic Turkish Studies, 12(6).

Jurdi, R., Hage, H. S., \& Chow, H. P. (2011). Academic dishonesty in the Canadian classroom: Behaviours of a sample of university students. Canadian Journal of Higher Education, 41(3), 1-35.

Karım, S., \& Ghavam, E. (2011). The relationship between self-control, self-effectiveness, academic performance and tendency towards academic cheating: A case report of a university survey in Iran. Malaysian Journal of Distance Education, 13(2), 1-8.

Kılıçoğlu, O. (2007). Hiæ̧met içi eğitimde kullanım artan web tabanl eğitim yöntemi ve bir uygulama. Yüksek lisans tezi. Marmara Üniversitesi Sosyal Bilimler Enstitüsü, İstanbul.

Kline, R. B. (2005). Principles and practice of structural equations modeling (2nd ed). New York: Guilford.

Kerkvliet J., \& Sigmund C. L. (1999). Can we control cheating in the classroom? The Journal of Economic Education, 30(4), 331-343.

Kibler, W. L. (1993). A framework for addressing academic dishonesty from a student development perspective. NASPA Journal, 31(1), 8-18.

Köse, Ö. ve Arıkan. A. (2011). Reducing plagiarism by using online software: An experimental study. Contemporary Online Language Education Journal, 1, 122-129.

Memduhoğlu, H. B. ve Tayiz, V. (2016). Eğitim fakültesi öğrencilerinin akademik sahtekârlık eğilimlerinin değerlendirilmesi. 15. Uluslararası Sınf Ö̆gretmenliği Eğitimi Sempozyumu Tam Metin Bildiriler Kitabı içinde (s.629- 639).

Nora, W. L. Y., \& Zhang, K. C. (2010). Motives of cheating among secondary students: The role of self-efficacy and peer influence. Asia Pacific Education Review, 11(4), 573-584.

Leech, N. L., Barrett, K. C., \& Morgan, G. A. (2008). SPSS for intermediate statistics: Use and interpretation. New York: L. Erlbaum Associates.

Lanier, M. M. (2006). Academic integrity and distance learning. Journal of Criminal Justice Education, 17(2), $244-261$.

Lambert, E. G., Hogan, N. L., \& Barton, S. M. (2003). Collegiate academic dishonesty revisited: What have they done, how often have they done it, who does it, and why did they do it? Electronic Journal of Sociology, 7(4), 1-27.

Murdock, T. B., \& Anderman, E. M. (2006). Motivational perspectives on student cheating: Toward an integrated model of academic dishonesty. Educational Psychologist, 41(3), 129-145.

32-Maurer, H., Kappe, F., ve Zaka, B. (2006). Plagiarism-A Survey. Journal of Universal Computer Science, 12 (8), 1050 1084.

Quaye, B. R. (2013). How the course context affects students' decisions about academic dishonesty. In Lilly International Conference on College Teaching.

Ömür, Y. E., Aydın, R. ve Argon, T. (2014). Olumsuz değerlendirilme korkusu ve akademik sahtekârlık. Eğitim ve Insani Bilimler Dergisi, 5 (9), 131-149.

Özden, M., ve Özdemir Özden, D. (2015). Öğretmen adaylarına göre akademik usulsüzlük davranışları. Yükesekögretim ve Bilim Dergisi, 5 (1), 88-98.

Roth, N. L., \& McCabe, D. L. (1995). Communication strategies for addressing academic dishonesty. Journal of College Student Development, 36(6), 531-541.

Stubbings, R., \& Brine, A. (2003). Plagiarism and the role of the library. Library \& Information Update, 2(12), 42-44.

Swift, C. O. ve Nonis, S. (1998). When no one is watching: Cheating behavior on projects and assignments. Marketing Education Review, 8 (1), 27-36.

Seven, M. A. ve Engin, A. O. (2008). Eğitim fakültesi öğrencilerinin kopya çekmeye duydukları ihtiyaç ve kopya çekme sebepleri. Atatürk Üniversitesi S.B.E. Dergisi, 11 (1),121-136.

Şencan, H. (2005). Sosyal ve davranışsal ölçümlerde güvenilirlike ve geçerlilik. Ankara: Seçkin Yayınevi.

Şahin, C.. ve Altınay, Y. B. (2009, 1-3 Mayıs). İlköğretim 1. kademedeki ögrencilerin düsünme becerilerini ve yaratıcllklarmı geliștirmek amacuyla aktif araștırmac olarak araștırma tekniklerini kullanma becerilerinin değerlendirilmesi. The First International Congress of Educational Research, Onsekiz Mart Üniversitesi, Çanakkale.

Şentürk, L. ve Aktaş, E. (2015). Türkiye'de ve Romanya'da okutulan ana dili Türkçe ders kitaplarının değer iletimi açısından karşılaştırılması. Değerler Eğitimi Dergisi, 13 (29), 215-243.

Şimşek, Ö.F. (2007). Yapısal eşitlik modellemesine giriş: Temel ilkeler ve lisrel uygulamalar. Ankara: Ekinoks Yayınları.

Tabachnick, B. G., \& Fidell, L. S. (2007). Using multivariate statistics. 5. basim. Boston: Pearson Education.

Tadesse, T., \& Getachew, K. (2010). An exploration of undergraduate students' selfreported academic dishonesty at Addis Ababa and Jimma Universities. Ethiopian Journal of Education and Sciences, 5(2), 77-99.

Thomas, D. (2017). Factors that explain academic dishonesty among University Students in Thailand. Ethics \& Behavior, 27(2), 140-154.

Türk Dil Kurumu, Büyüke Türkşe Sözllïk, 16 Aralı 2018 tarihinde http://www.tdk.gov.tr/index.php?option $=$ com bts\&arama=kelime\&guid=TDK.GTS.5c1572ce29df55.978780 19 adresinden erişildi. 
Tan, Ş. (2001). Sınavlarda kopya çekmeyi önlemeye yönelik önlemler. Eğitim ve Bilim, 26(122).

Topsakal, C. (2011). Eğitim fakültesi öğretmen adaylarının aldıkları disiplin cezaları üzerinde bir inceleme. Türkiye Adalet Akademisi Dergisi, 1 (7), 287-316.

Tüba (Türkiye Bilimler Akademisi). (2000). Bilimsel araştırmalarda etik ve sorunlar. Ankara: TÜBA

Whitley, B. E., Jr. (1998). Factors associated with cheating among college students: A review. Research in Higher Education, 39 (3), 235-274.

Yangın, S. ve Kahyaoğlu, M., İlköğretim Öğretmen Adaylarının Kopya Çekmeye Yönelik Tutum ve Görüşleri, Balkeesir Universitesi Sosyal Bilimler Dergisi, 12 (21), 2009, 46-55.

Yıldırım, S. (2015). Üniversite ögrencilerinin akademik başar, akademik erteleme, kopya çekme ve devamsı̨̧hk durumlarmın yordayıcısı olarak sosyal bağhlık. Yüksek lisans tezi. Sosyal Bilimler Enstitüsü, Gaziosmanpaşa Üniversitesi, Tokat.

Zimerman, M. (2012). Digital natives, searching behavior and the library. New Library World, 113(3-4), $174-201$.

\section{EXTENDED ABSTRACT}

Education is the process of providing individuals with desired behaviors (Kilıçoğlu, 2007; Baysen, Baysen \& Çakmak, 2017). However, unethical behavior patterns can also be observed in students during this educational process (Plane \& Ünal, 2015). Among the unethical behaviors, the most exhibited behavior by students is academic dishonesty. Academic dishonesty is defined as all of the situations that students perform with behaviors such as cheating, plagiarizing, fabricating and breaking information that does not belong to them in an academic research, exam or projects (Kibler, 1993; Ömür, Aydın, \& Argon, 2014). This concept is a multi-dimensional and widespread negative student behavior (Ferrari, 2005; Imran \& Nordin, 2013; Ikupa, 1997). Academic dishonesty behavior is gradually increasing at all levels of the education level, and this is beginning to become worrisome (Tadesse \& Getachew, 2010; Uçak \& Ünal, 2015; Whitley, 1998). Because the developing and changing today's information technologies and the intensive use of these technologies by students cause an increase in the frequency of showing academic dishonesty behavior (Aslantaş \& Acar, 2008; Hançer, 2017; Lin \& Wen, 2007).

The most important concept that is evaluated within the scope of academic dishonesty is cheating behavior. The concept of copy is defined as "imitation of a work of art or written text", "copying work", "secretly using someone or another place to answer questions in an exam" (TDK, 2018). Although it is stated in the researches that university students do not see their copy behaviors as normal, it is noteworthy that this behavior is the most common academic dishonesty among students (Aluede, Omoregie \& OsaEdoh, 2006; Barzegar \& Khezri, 2012; Eminoğlu,2008). On the other hand, cheating behavior is a type of academic dishonesty that prevents the measurement and evaluation activities (exams, homework, projects, etc.) from being valid and reliable (Ay \& Çakmak, 2015). Therefore, preventing academic dishonesty behavior in the form of cheating and determining why students resort to academic dishonesty behavior plays an important role in improving the quality of education and training.

Another academic fraud behavior is plagiarism. Plagiarism is the case of using someone else's ideas and opinions without showing the source information (Özenç-Ünal \& Uçak, 2015). In other words, plagiarism is defined as the presentation of an idea belonging to someone else as a part of a work, in whole or in part (TÜBA, 2000). It is stated that the plagiarism behavior occurs in a deliberate and unintentional way by the students (Maurer ve arkadaşlarl; 2006). However, since this behavior may cause erroneous evaluations such as cheating behavior in the measurement and evaluation system, it is important to identify the causes. In the researches, it was concluded that students' plagiarism behavior was caused by the lack of knowledge in reporting and scientific writing (Avaroğullar1, 2012; Köse \& Arıkan, 2011; Dey ve Sobhan, 2006).

It is important to know the academic dishonesty behaviors that affect the quality of education and assessment and evaluation processes in advance and to determine the causes of students' academic dishonesty behavior in many ways. When the literature is examined in the literature, it is seen that there is only one measurement tool on academic fraud (Eminoğlu, 2008). On the other hand, it is seen that there are some measurement tools for evaluating cheating behavior (Ay \& Çakma, 2015). However, when the literature is examined, it is noteworthy that cheating behavior constitutes only one dimension of academic fraud behavior. For all these reasons, this study aimed to adapt the Academic Dishonesty Scale, which consists of 6 dimensions and 23 items, developed by Bahsir and Bala (2017) into Turkish. This study is thought to contribute to the multi-dimensional evaluation of students' academic dishonesty levels.

For this, it was aimed primarily to test the validity of the language, and both the English and Turkish forms of the scale were applied to a group who knew these two languages. After the application, the 
correlation coefficient between the scores obtained from both forms was calculated and it was found that there was a highly significant relationship between the Turkish and English forms of the scale $(\mathrm{r}=.95 ; \mathrm{p}$ $<.001)$. At the same time, the dependent groups $t$ test was analyzed to examine the relationship between the scores obtained from the Turkish and English forms of the scale. As a result of the analysis, it was determined that the difference between the scores obtained from the two forms was not significant ( $t$ (19) $=.725 ; \mathrm{p}=.49 ; \mathrm{p}>.05)$. These results indicate that the Turkish and English forms of the scale are perceived in the same way by the readers and linguistically validity is provided.

After the language validity was provided, the construct validity of the scale was examined by confirmatory factor analysis. First level factor analysis was performed in the study and it was seen that the obtained model fit indices were at an acceptable level $\left(x^{2} / d f=3.21 \mathrm{GFI}=.98\right.$, IFI $=.93, \mathrm{CFI}=.93$, NFI $=.91 \mathrm{AFGI}=.97$ and RMSEA. $=.073)$. Afterwards, a second-order confirmatory factor analysis was performed to examine whether the implicit structure of the scale was confirmed and it was seen that the model fit indexes obtained were within acceptable limits $\left(x^{2} / d f=3.22\right.$ GFI $=.97$, IFI $=.93$, CFI $=.93$, $\mathrm{AFGI}=.97$ and RMSEA = .074). First and second level confirmatory factor analysis results indicate that the Academic Dishonesty Scale has been validated for the Turkish sample and is a valid measurement tool.

According to the analysis made to see if the scale made a discriminatory measurement, it was revealed that the difference between the item score averages obtained from the $27 \%$ lower and $27 \%$ upper groups was significant for all items at $\mathrm{p}<.001$ level. Cronbach Alpha internal consistency coefficient was calculated for the reliability analysis of the scale. According to the results, the measurements made were found to be reliable. As a result, in the adaptation study, it was revealed that the Academic Dishonesty Scale was verified on the data obtained from the Turkish sample. These results can be interpreted as the measuring tool will give valid and reliable results in future studies.

\section{AKADEMİK SAHTEKÂRLIK ÖLÇEĞİ}

Açıklama: Geçen bir yıl içindeki gerçekleştirme düzeyinizi değerlendiriniz. Her bir ifadeyi dikkatlice okuduktan sonra ilgili ifadeye yönelik gerçekleştirme düzeyinizi; Her Zaman, S1k Sık, Bazen, Nadiren ve Hiç seçeneklerinden size en uygun olanı seçerek belirtiniz. Tüm ifadeleri dürüst bir şekilde cevaplama konusunda kendinizi rahat hissediniz. İfadelerin hiçbirinde doğru ya da yanlış cevap bulunmamaktadır. Verdiğiniz cevaplarınız gizli tutulacaktır. Lütfen maddeleri okuduktan sonra aklınıza gelen ilk seçeneği işaretlemeye çalışınız.

\begin{tabular}{|c|c|c|c|c|c|}
\hline$\overline{\text { Maddeler }}$ & Her Zaman & Sik S1k & Bazen & Nadiren & Hiç \\
\hline $\begin{array}{l}\text { 1. Sınav esnasında arkadaşlarımdan } \\
\text { cevapları alabilmek için işaretler } \\
\text { kullanırım (göz kırma, bakışma, el } \\
\text { işaretleri) }\end{array}$ & & & & & \\
\hline $\begin{array}{l}\text { 2.Sınav esnasında gizli notlar, hesap } \\
\text { makinası ve diğer elektronik cihazlar gibi } \\
\text { yasaklı şeyler kullanırım. }\end{array}$ & & & & & \\
\hline $\begin{array}{l}\text { 3. Cevap kâğıdımı sınav salonundaki } \\
\text { diğ ger öğrencilerle değiştiririm. }\end{array}$ & & & & & \\
\hline $\begin{array}{l}\text { 4. Sınav esnasında soru kâğıdına } \\
\text { cevapları yazar ve sınıf arkadaşlarıma } \\
\text { cevapları veririm. }\end{array}$ & & & & & \\
\hline $\begin{array}{l}\text { 5. Sinavda boyunca başka öğrencilerden } \\
\text { kopya çekmeye çalışırım. }\end{array}$ & & & & & \\
\hline $\begin{array}{l}\text { 6. Bir hikaye/şiir/bölüm özetini bir ders } \\
\text { kitabından kopyalar ve bunun benim } \\
\text { tarafımdan hazırlandığını belirtirim. }\end{array}$ & & & & & \\
\hline $\begin{array}{l}\text { 7. Ödev tesliminde diğer kaynaklardan } \\
\text { aldığım cümle/satır/kelime ve kalıpların } \\
\text { çok azını değiștir ve kopyalarım. }\end{array}$ & & & & & \\
\hline $\begin{array}{l}\text { 8.Eğitimle ilgili kişisel ödev/projemde } \\
\text { kullandığım online kaynakların yazarını } \\
\text { belirtmem/atıfta bulunmam. }\end{array}$ & & & & & \\
\hline $\begin{array}{l}\text { 9. İnternette kişisel yorumlar almak için } \\
\text { bilimsel bilgileri manipüle eder ve benim } \\
\text { tarafımdan yazılmıș gibi sunarım. }\end{array}$ & & & & & \\
\hline 10.Sınavda özel bir yardım almak için & & & & & \\
\hline
\end{tabular}




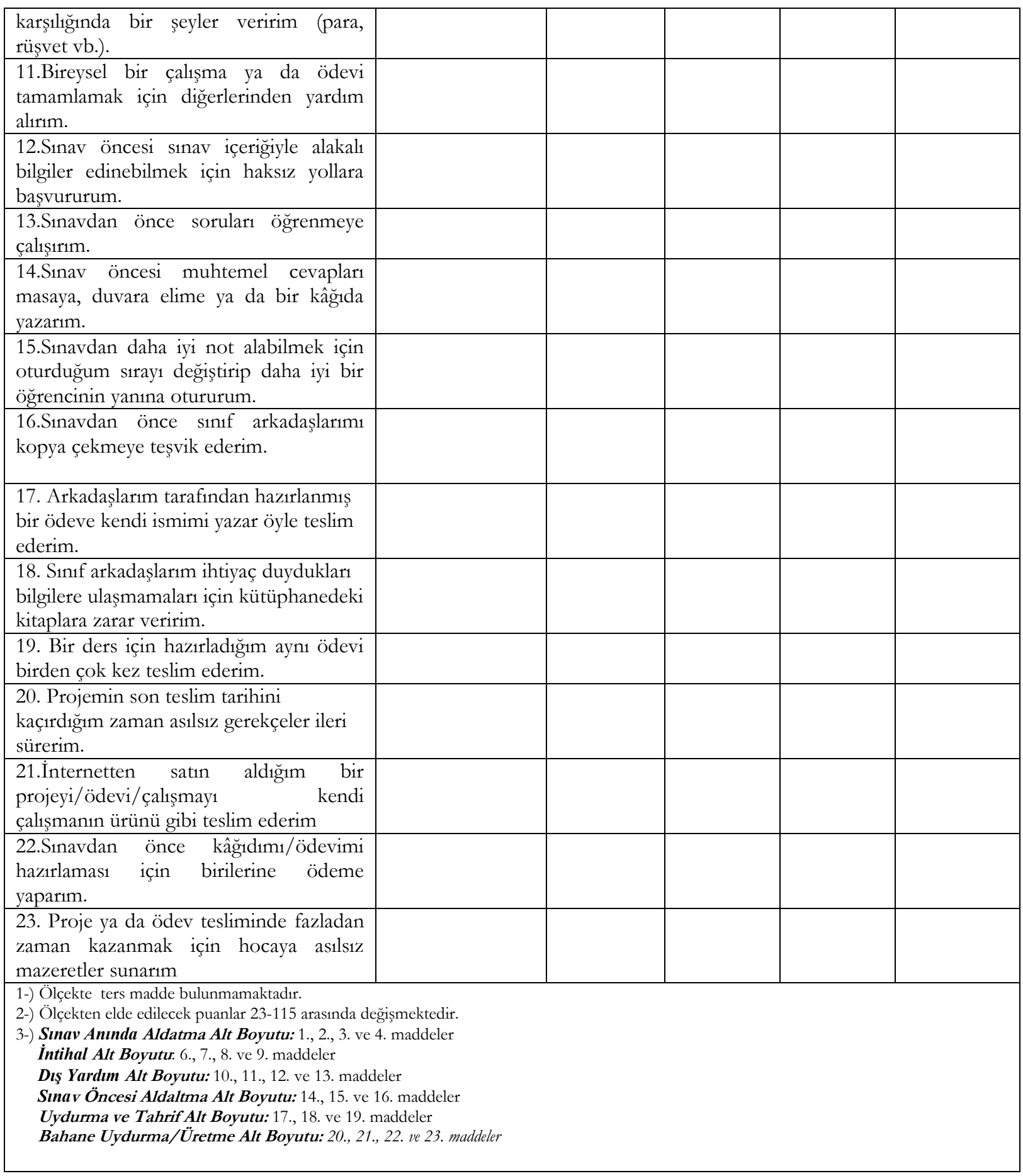

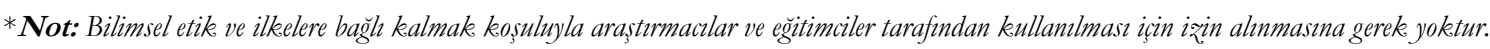

